\title{
CLINICAL PRACTICE \\ Odyssean malaria outbreaks in Gauteng Province, South Africa, 2007 - 2013
}

\author{
J Frean, B Brooke, J Thomas, L Blumberg
}

John Frean, Lucille Blumberg and Juno Thomas are medical microbiologists in divisions of the National Institute for Communicable Diseases, Johannesburg, South Africa, dealing with malaria diagnosis, surveillance and outbreak response, respectively. Basil Brooke is an NICD entomologist with special expertise in malaria vector mosquitoes and mechanisms of insecticide resistance. Professors Frean and Blumberg and Dr Brooke are also affiliated to the Wits Research Institute for Malaria, Faculty of Health Sciences, University of the Witwatersrand, Johannesburg.

\section{Corresponding author: J Frean (johnf@nicd.ac.za)}

\begin{abstract}
Background. Odyssean malaria refers to malaria transmitted by translocated mosquitoes and is a diagnosis of exclusion, as the probability of finding the responsible vector is miniscule. We believe that road traffic from endemic areas in and around South Africa is the source of most of the infected mosquitoes. Because of the unexpected nature of the disease, diagnosis is often delayed and severe and complicated malaria is common.

Objectives. To describe outbreaks of odyssean malaria during the period 2007 through 2013 in Gauteng Province, South Africa, and to educate healthcare workers about this form of malaria.

Methods. Site visits, environmental hygiene inspections, patient interviews, and entomological investigations for adult mosquitoes and larvae in potential breeding sites were done in each identified outbreak.

Results. Over the period, 14 laboratory-proven and 7 probable cases of odyssean malaria were investigated. There were 2 deaths $(9.5 \%$ case fatality rate, approximately 10 times higher than the national fatality rate for malaria). We describe two recent clusters of cases in detail, and emphasise the importance of clinician awareness of this rare but frequently severe form of malaria.

Conclusion. Odyssean malaria cases are inevitable in South Africa, given the volume of road, rail and air traffic from malaria risk areas into Gauteng and other non-endemic provinces. It is likely that many cases are missed, owing to the rare and sporadic nature of the condition. Malaria should always be kept in mind as a cause of unexplained fever and thrombocytopenia, even in the absence of a travel history.
\end{abstract}

S Afr Med J 2014;104(5):335-338. DOI:10.7196/SAMJ.7684

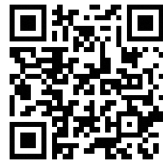

The acquisition of malaria outside endemic areas is inherently unexpected, which delays diagnosis and treatment, and is therefore disproportionately associated with severe illness or a fatal outcome. The recognition in the 1970s in Europe of such cases of 'airport malaria' (and its subsidiaries suitcase, baggage or luggage malaria) led to the awareness that aircraft are not the only vehicles that can transport vector mosquitoes out of their normal habitats, and the entities of harbour, container, and minibus (or taxi rank) malaria were described. ${ }^{[1,2]}$ To unify this plethora of essentially equivalent descriptions, the term 'odyssean malaria' was coined. ${ }^{[3]}$ Odysseus was the legendary Greek hero who, on his way home from the 
Trojan wars, wandered the Mediterranean region, experiencing many adventures and narrow escapes. Similarly, a lost mosquito might have many dangerous encounters as she navigates a suitcase, aircraft cabin, cargo hold or taxi, escaping being deliberately swatted, accidentally squashed, eaten by a predator, or succumbing to heat or cold on her way to her next blood meal, far from her natural home.

Between 1996 and 2004, we accumulated 46 cases of odyssean malaria in Gauteng Province, South Africa (SA) (Table 1). ${ }^{[1]}$ These patients are clearly at risk of substantially higher mortality compared with the national malaria case fatality rate, and given SA's position at the southernmost extent of malaria transmission on the continent, attract intense local media interest and speculation about spread of malaria to this (non-endemic) province. No odyssean malaria cases were noted in 2005 and 2006 (although we believe that several cases are missed every year), but we have investigated cases in nearly every malaria season since then, including two outbreaks in the $2012-2013$ season. We discuss the clinical and public health aspects of this frequently severe form of malaria.

\section{Methods \\ Case definition}

A case of odyssean malaria is one in which there is no travel history, and the possibility of mechanical transmission (by blood transfusion, injection or needlestick injury) is excluded. Malaria is a notifiable medical condition. Most cases came to our attention through local health authorities in the course of their investigations of notifications, when we were requested to help with clinical, epidemiological and entomological aspects.

\section{Case investigations}

Clinical details were obtained from doctors caring for the patients. Outbreaks were investigated in conjunction with local health officials, including environmental health officers. Site visits were undertaken and, where possible, surviving patients and their families

were interviewed and detailed clinical and travel histories obtained. Adult mosquitoes, when present, were caught inside houses and other buildings around the patients' dwellings. Mosquito larvae were collected from surface water bodies and containers, if such breeding sites were found. Standard entomological techniques were used to identify mosquitoes to species level.

\section{Results}

Eight outbreaks were investigated during the study period, yielding 14 laboratory-proven and 7 probable cases of odyssean malaria. There were 2 deaths $(9.5 \%$ case fatality rate, approximately 10 times greater than the current national case fatality rate for malaria, and nearly 20 times the national target of $0.5 \%$ ) (Table 2). The most recent outbreaks are described in detail.

\section{Outbreak 1}

A couple living on a smallholding in Donkerhoek/Mooiplaats, on the eastern outskirts of Pretoria, Gauteng Province, experienced

Table 1. Odyssean malaria in Gauteng Province, South Africa, $1996-2004^{[1]}$

\begin{tabular}{ll}
\hline $\begin{array}{l}\text { Total number of cases identified } \\
\text { Time to diagnosis after onset, } \\
\text { median (range) }\end{array}$ & 46 \\
$\begin{array}{l}\text { Most frequent initial clinical } \\
\text { diagnoses }\end{array}$ & $\begin{array}{l}\text { Influenza, viral hepatitis, } \\
\text { septicaemia }\end{array}$ \\
$\begin{array}{l}\text { Proportion of patients with } \\
\text { thrombocytopenia }\end{array}$ & $80 \%$ \\
$\begin{array}{l}\text { Malaria species involved } \\
\text { Case fatality rate }\end{array}$ & All Plasmodium falciparum \\
$\begin{array}{l}\text { National malaria case fatality rate } \\
\text { (1999 - 2005) }\end{array}$ & 0.6 - $1 \%$
\end{tabular}

Table 2. Odyssean malaria cases, Gauteng Province, 2007 - 2013

\begin{tabular}{|c|c|c|c|c|c|}
\hline Year & Cases & Outcome & Species & Location of outbreak & Putative source/s of mosquito \\
\hline 2007 & 1 & Survived & P. ovale & $\begin{array}{l}\text { Johannesburg, Gauteng } \\
\text { Province }\end{array}$ & $\begin{array}{l}\text { Patient's car had gone on loan to LP and } \\
\text { returned recently }\end{array}$ \\
\hline 2009 & 2 (siblings) & Survived & P. falciparum & $\begin{array}{l}\text { Heidelberg, Gauteng } \\
\text { Province }\end{array}$ & $\begin{array}{l}\text { Near road and railway to MP; Mozambican } \\
\text { neighbour }\end{array}$ \\
\hline \multirow[t]{2}{*}{2010} & 2 (siblings) & Survived & P. falciparum & Soweto, Gauteng Province & $\begin{array}{l}\text { Possibly LP, via neighbour who had visited } \\
\text { there recently }\end{array}$ \\
\hline & $\begin{array}{l}3 \text { (father and } \\
\text { siblings) }\end{array}$ & $\begin{array}{l}2 \text { survived } \\
1 \text { fatal }\end{array}$ & $\begin{array}{l}\text { P. falciparum } \\
\text { P. falciparum } \text { presumed }^{+}\end{array}$ & Soweto, Gauteng Province & $\begin{array}{l}\text { Not known; residence } 1 \mathrm{~km} \text { away from above } \\
\text { cluster }\end{array}$ \\
\hline \multirow[t]{2}{*}{ Jan. 2012} & 3 (unrelated) & Survived & P. falciparum presumed ${ }^{+}$ & $\begin{array}{l}\text { Soshanguve, Gauteng } \\
\text { Province }\end{array}$ & Not known \\
\hline & 3 (unrelated) & Survived & P. falciparum presumed ${ }^{+}$ & $\begin{array}{l}\text { Pretoria East, Gauteng } \\
\text { Province }\end{array}$ & $\begin{array}{l}\text { Mozambican and Zimbabwean labourers } \\
\text { living nearby }\end{array}$ \\
\hline Dec. $2012^{*}$ & $\begin{array}{l}3 \text { (2 spouses, } \\
1 \text { unrelated) }\end{array}$ & $\begin{array}{l}2 \text { survived } \\
1 \text { fatal }\end{array}$ & P. falciparum & $\begin{array}{l}\text { Donkerhoek, Gauteng } \\
\text { Province }\end{array}$ & $\begin{array}{l}\text { Near highway toll plaza; Mozambican } \\
\text { labourers living nearby; tyre importer nearby }\end{array}$ \\
\hline Jan. $2013^{*}$ & $\begin{array}{l}4 \text { ( } 2 \text { father and } \\
\text { son; } 2 \text { unrelated) }\end{array}$ & 4 survived & P. falciparum & $\begin{array}{l}\text { Kempton Park, Gauteng } \\
\text { Province }\end{array}$ & $\begin{array}{l}\text { Wife and mother of cases } 1 \text { and } 2 \text { had returned } \\
\text { from LP recently; case } 3 \text { worked at a police } \\
\text { station with illegal immigrants; father of case } 4 \\
\text { recently returned from Angola }\end{array}$ \\
\hline \multicolumn{6}{|c|}{ LP $=$ Limpopo Province; $\mathrm{MP}=$ Mpumalanga Province. } \\
\hline \multicolumn{6}{|c|}{${ }^{*}$ Outbreaks described in detail in this article. } \\
\hline \multicolumn{6}{|c|}{${ }^{\dagger}$ Reported as malaria cases by local health authorities, but confirmatory laboratory reports were not available. } \\
\hline
\end{tabular}


onset of influenza-like symptoms on 22 December 2012. The husband (46 years old) developed chest pain, for which he was admitted to a tertiary hospital. His wife (34 years old) collapsed at home the following day and was hospitalised. Despite the absence of a travel history, Plasmodium falciparum antigen tests and blood smears were requested in both cases by the attending clinicians. P. falciparum antigen tests were positive in both cases, with parasitaemia counts of $2 \%$ and $<1 \%$ reported for the wife and husband, respectively. Both had complications requiring intensive care, but recovered. A 46-year-old woman living on the neighbouring plot in Donkerhoek/Mooiplaats became ill on 25 December 2012 while on a vacation trip along the Orange River in southern Namibia, a non-transmission area for malaria. Her symptoms worsened and she was taken to a healthcare facility in the Northern Cape Province on 1 January 2013, where she was treated for 'exhaustion. On returning home, she was admitted to hospital on 4 January 2013, critically ill. Investigations were done for malaria; the P. falciparum antigen test was positive, and a parasitaemia of $23 \%$ noted. Unfortunately, this patient had numerous malaria-related complications and died 3 days later.

\section{Outbreak 2}

On 17 January 2013, 3 cases of laboratory-confirmed malaria were reported at a private hospital in Kempton Park (a suburb of Ekurhuleni Municipality, east of Johannesburg, Gauteng Province), as follows. A 30-year-old woman was admitted on 13 January 2013 and subsequently diagnosed with cerebral malaria ( $P$. falciparum antigen-positive, $33.4 \%$ parasitaemia). Her only recent travel had been to Rustenburg, North West Province (a non-malaria-endemic area) for 2 days over Christmas. An unrelated 41-year-old man was admitted on 16 January 2013 and diagnosed with malaria (positive $P$. falciparum antigen test, $0.8 \%$ parasitaemia); he subsequently required intensive care. His 12-year-old son was admitted on 17 January 2012, with uncomplicated malaria (P. falciparum antigen test positive, $3.5 \%$ parasitaemia). The father and son lived in the same house in a Kempton Park suburb, a few blocks from the home of the first case. A 12-year-old boy with haemophilia (factor VIII-deficient), living within walking distance of the other 3 cases, developed fever on 14 January 2013, initially thought to be associated with intraarticular injections administered the day before. He was subsequently admitted to a Johannesburg hospital on 30 January 2013 with uncomplicated $P$. falciparum malaria. Despite the delayed diagnosis, he responded well to treatment and was subsequently discharged. There was no clinical or epidemiological evidence that the malaria infection was related to the haemophilia therapy.

\section{Entomological investigations}

None of the adult or larval mosquitoes collected were malaria vectors, and no anopheline mosquito breeding sites were found (Fig. 1). In the first cluster, the two affected houses were close together (approximately $300 \mathrm{~m}$ separation, on adjacent plots) and the same infected mosquito/es could have infected all the patients. Mozambican labourers were resident on one of the properties, and a national highway toll plaza and a tyre warehouse that allegedly imported tyres from Zambia were both a few hundred metres away, and therefore could plausibly have been the source of the mosquito or mosquitoes. The highway in question is a main route to Mpumalanga Province and Mozambique, both malaria transmission areas. In the second cluster, an international airport and major highway were less than $5 \mathrm{~km}$ away, but rather too far for mosquito dispersal. Other possible sources for infected mosquitoes were identified (Table 2), but as is usual in odyssean malaria outbreaks, these are speculative.

\section{Discussion}

\section{Clinical aspects of odyssean malaria}

The importance of odyssean malaria is related to the frequently delayed or missed diagnosis of the cause of illness in affected patients, with associated high rates of complications and mortality. Absence of a history of travel to a malaria-endemic area is almost always responsible for the delayed diagnosis. In some cases, the diagnosis is only made at autopsy. ${ }^{[2]}$ The risk of a tragic outcome can, however, be reduced if clinicians in non-endemic areas are alerted to the existence of this form of malaria transmission, and educated accordingly.

Malaria parasites should routinely be sought in one or more successive blood films of any febrile patient in whom a diagnosis is not readily apparent, especially if the platelet count is low. Unexplained jaundice, depressed consciousness or coma, and apparent 'sepsis' that is unresponsive to antibiotics are common clinical presentations in these cases. Clinicians should specifically request malaria examinations and should not assume that these will automatically be done when a full blood count is requested. Since thrombocytopenia is a very common, although not invariable, finding in patients with both uncomplicated and severe malaria, its unexplained presence in a febrile patient should alert the physician to the possibility of malaria.

Quantitative parasite counts should always be requested, as these give an indication of the severity of illness and are useful in monitoring the response to treatment. The presence of falciparum gametocytes on blood films indicates the presence of malaria infection of at least 10 days' duration (but frequently 3 weeks or longer), and hence the possibility of missed or delayed infection. Point-of-care (rapid diagnostic) malaria tests should be more widely utilised when routine laboratory diagnosis is delayed or not available, such as in primary health clinics (provided users are appropriately trained). Inexperience in recognising and managing clinically severe malaria contributes to mortality, ${ }^{[4]}$ and patients should be managed at the highest level of care available.

The apparent decrease in odyssean malaria during the period under review, compared with the previous series (Table 1), is probably largely due to SA's sustained success in controlling malaria since $2000,{ }^{[5]}$ but odyssean malaria will remain a risk in the nonendemic provinces until malaria is eliminated in the region.

\section{Epidemiological aspects of odyssean malaria}

In $\mathrm{SA}$ active malaria transmission is restricted to regions bordering on Mozambique, Zimbabwe and, to a much lesser extent, Botswana. ${ }^{[6]}$ Road transport from malarious areas is undoubtedly more important than air transport as a source of translocated mosquito vectors. Gauteng Province is the economic hub of SA. It is a non-transmission area for malaria because of its altitude and climate, although it carries about $20 \%$ of the country's malaria burden in the form of imported cases ${ }^{[7]}$ Any malaria-infective mosquitoes in Gauteng Province must therefore have been transported from a malaria-affected region. Within Gauteng Province, the Johannesburg-Pretoria metropole is the destination of a large volume of road passenger and freight traffic from neighbouring countries, mainly Mozambique and Zimbabwe, as well as from the malaria risk regions within SA.

In southern Africa, Anopheles arabiensis and A. funestus are the principal vectors of malaria, ${ }^{[8]}$ and are most likely to be responsible for the odyssean malaria cases recorded in Gauteng. Escaping from a vehicle, a travelling mosquito is likely to seek a nearby indoor resting site, especially if it is a malaria vector species that prefers to bite humans. Depending on its physiological state, it is then likely to acquire one or several blood meals from the household occupants after dusk. In general, a malaria vector mosquito is not likely to fly further 
than $1.5 \mathrm{~km}^{[9]}$ or to survive longer than approximately 1 month, during which period she is potentially able to infect several people in a short space of time, even in a single night. ${ }^{[10,11]}$

\section{Investigation of odyssean malaria outbreaks}

Assuming it has been established that the infected person/s have no recent travel history to a malaria-affected region, and mechanical transmission has been excluded, the following questions are pertinent from an outbreak investigation aspect: (i) Do they live in close proximity to a national highway, airport, train station, bus depot, taxi rank or other public transport node? (ii) Have any of their neighbours, or other persons living in close proximity, travelled to a malariaaffected region during the past 2 - 3 weeks? (iii) Did they notice the unusual presence of any mosquitoes or mosquito bites on their person during the past 2 - 3 weeks? and (iv) Do they use insecticides in the home? During entomological investigations in households where odyssean malaria has occurred, places to search for culprit mosquitoes are indoors in dark crevices, under furniture, and in or behind hanging clothing. Because the time lag from receiving a malaria-infective bite to onset of the first symptoms is usually at least 10 days to 2 weeks, the chances of finding the culprit Anopheles female are very small indeed. Bodies of standing water (large or small, natural or artificial) near dwellings where malaria infections have been acquired should be investigated for the presence of anopheline mosquito larvae (Fig. 1), as there is always a chance that localised breeding is temporarily taking place if the weather is suitable, and there is potential for propagated outbreaks if gametocyte carriers are present in the local community.

Two additional unrelated incidents of odyssean malaria occurred in January 2014 in communities on the southern edge of Johannesburg. Both patients survived, although diagnosis and therapy was delayed in one patient, who developed severe and complicated malaria and required intensive care. For details visit http://www.nicd.ac.za/assets/ files/Malaria(2).pdf.

Acknowledgements. We thank all the communicable disease control coordinators, environmental health officers, healthcare workers, local health authorities, and staff and students of the Vector Control Reference Laboratory and Outbreak Response Unit, National Institute for Communicable Diseases, who assisted in the outbreak investigations.

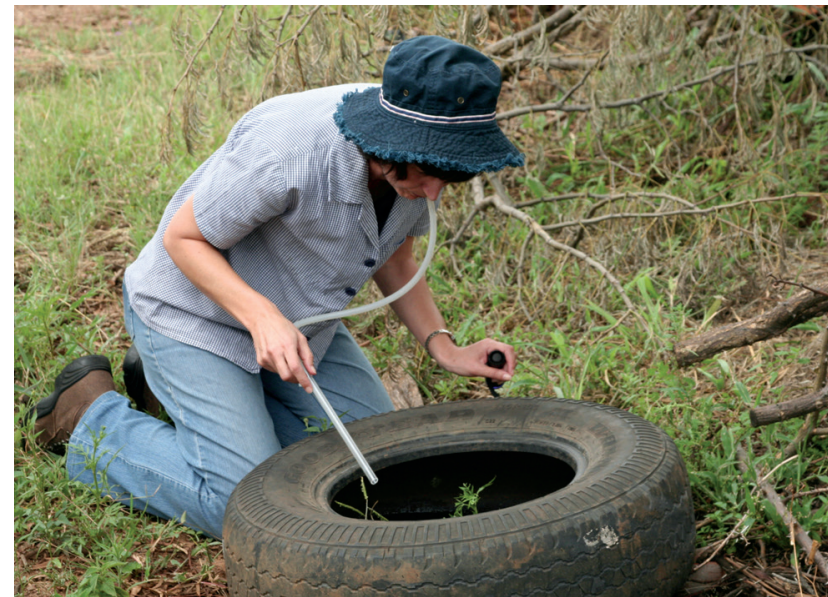

Fig. 1. Odyssean malaria, outbreak 1. Hunting mosquitoes in a discarded tyre, a potential breeding and resting site (by kind permission of Professor Lizette Koekemoer, National Institute for Communicable Diseases).

1. Frean JA, Blumberg L. Odyssean and non-mosquito-transmitted forms of malaria. In: SchlagenhaufLawlor P, ed. Travelers' Malaria. Hamilton, Ontario: BC Decker Inc., 2008

2. Isaäcson M. Airport malaria: A review. Bull World Health Organ 1989;67(6):737-743.

3. Isaäcson M, Frean JA. African malaria vectors in European aircraft [Letter 2: Odyssean malaria]. Lancet 2001;357(9251):235. [http://dx.doi.org/10.1016\%2FS0140-6736\%2805\%2971340-4]

4. Mehta U, Durrheim DN, Blumberg L, et al. Malaria deaths as sentinel events to monitor healthcare delivery and antimalarial drug safety. Trop Med Int Health 2007;12(5):617-628. [http://dx.doi org/10.1111/j.1365-3156.2007.01823.x]

5. Maharaj R, Raman J, Morris N, et al. Epidemiology of malaria in South Africa: From control to elimination. S Afr Med J 2013;103(10):779-783. [http://dx.doi.org/10.7196/SAMJ.7441]

6. Sinka ME, Bangs MJ, Manguin S, et al. A global map of dominant malaria vectors. Parasit Vectors Sinka ME, Bangs MJ, Manguin S, et al. A global map of do
2012;5(1):69. [http://dx.doi.org/10.1186\%2F1756-3305-5-69]

2012;5(1):69. [http://dx.doi.org/10.1186\%2F1756-3305-5-69]

7. Sational Department of Health. Malaria Elimination Strategic Plan 2012-2018. Pretoria: $\mathrm{NDoH}, 2012$,
8. Sinka ME, Bangs MJ, Manguin S, et al. The dominant Anopheles vectors of human malaria in Africa, Europe and the Middle East: Occurrence data, distribution maps and bionomic précis. Parasit Vectors 2010;3(1):117. [http://dx.doi.org/10.1186\%2F1756-3305-3-117]

9. De Meillon B. The Anophelini of the Ethiopian Geographical Region. Johannesburg: South African Institute for Medical Research, 1947:120-122.

10. Gillies MT, Coetzee M. A Supplement to the Anophelinae of Africa South of the Sahara. Johannesburg South African Institute for Medical Research, 1987:79-81.

11. Beier JC. Frequent blood-feeding and restrictive sugar-feeding behavior enhance the malaria vector potential of Anopheles gambiae s.l. and An. funestus (Diptera: Culicidae) in western Kenya. J Med Entomol 1996;33(4):613-618

Accepted 21 November 2013. 